\title{
AS TRANSFORMAÇÕES DO REGIME JURÍDICO DA PROPRIEDADE PRIVADA: A INFLUÊNCIA NO DIREITO URBANÍSTICO
}

\author{
Angela Cassia Costaldello*
}

RESUMO: A autora aborda a influência do direito urbanístico na transformações do regime jurídico da propriedade privada; produtora de riqueza e permanentemente cambiante, adquire uma feição menos individualista e mais solidária, norteada pela harmonia entre o interesse privado e o público, objetivando a preservação da dignidade da pessoa humana.

1 À GUISA DE INTRODUÇÃO: O S F U N D A M E T T OS D A
PROPRIEDADE PRIVADA

O exame juridicamente adequado das influências sofridas pelo Direito Urbanístico contemporâneo em virtude da disciplina jurídica da propriedade privada, é imperativa a realização de prévia análise das transformações históricas ocorridas no próprio conceito, fundamentação e justificação teórica da propriedade.

Na modernidade, a propriedade privada foi içada a um dos pilares fundamentais da

\footnotetext{
* Professora Adjunta de Direito Administrativo da Faculdade de Direito da Universidade Federal do Paraná, Mestre e Doutora em Direito do Estado pela Universidade Federal do Paraná, Pós-doutoranda em Direito Administrativo pela Université Paris I - Panthéon Sorbonne; Procuradora-Geral do Ministério Público de Contas do Estado do Paraná.
}

organização política, econômica e social. ${ }^{1}$ Mostra-se indiscutível a sua condição constante de alicerce das relações sociais e a profundidade de sua influência na edificação do ideário jurídico contemporâneo, tanto público quanto privado.

Na malha de suas permanentes mutações históricas, ela emerge invariavelmente atrelada aos fatores que a circundam: condições sociais, econômicas e políticas determinantes da sua origem e desenvolvimento. Inúmeras foram as feições por ela tomadas no correr da História. ${ }^{2}$ Evidenciam-se as determinantes

${ }^{1}$ Profunda análise sobre a sociedade e as transformações do espaço realiza Manuel Castels, In: A Sociedade em Rede, tradução de Roneide Venâncio Majer, com a colaboração de Kaluss Brandini Gerhardt, 9. ed. São Paulo, Paz e Terra, 2006, p. 499 e ss.

${ }^{2}$ Acompanhando a análise histórica, a opinião de parte dos historiadores converge para a presença de três estágios percorridos pela propriedade privada e anota 
dessa evolução, em cada período histórico, com o realce dos interesses que a cercavam: fossem individuais, do proprietário, ou da coletividade. As variadas configurações que foram dadas à propriedade e às formas de aquisição e fruição são objeto de distante e densa polêmica, e, também, de investigação demonstrada em alguns ramos do conhecimento. ${ }^{3}$ Destacando a importância, amplitude e fluidez da propriedade, pronunciou-se Feliciano Benvenuti ${ }^{4}$ :

Gilissen que, inicialmente era coletiva, a seguir atinge a característica individual e absoluta, para, ao final, chegar à complexa composição entre o público e o privado, com vistas à coletividade "sem, contudo, exterminar com o individual". Afere que a natural tendência dos historiadores para traçar o desenvolvimento do instituto da propriedade conduzindo - sem fases intermediárias ou sobrepostas -, de um tipo a outro de propriedade (a propriedade primitiva seguida da propriedade dividida, esta sucedida pela individualista, e, por fim, a coletivista), mas que, em verdade, convivem sempre quatro tipos concomitantemente, ou, pelo menos, uma forma acabava por prevalecer, sem a eliminação das demais. Traz como exemplo a sociedade capitalista do século XIX, onde, apesar de ser prevalentemente individualista, persistiram traços das comunidades rurais de épocas anteriores. GILISSEN, John. Introdução histórica ao direito. Tradução de Antonio Manuel Hespanha e Manuel Macaísta Malheiros, Lisboa, Fundação Calouste Gulbenkian, 1986, p. 635. Tatam, também do assunto, dentre outros autores, OLIVEIRA, Fernando Andrade de. Limitações administrativas à propriedade privada imobiliária. Rio de Janeiro, Forense, 1982, p. 01.; PUGLIATTI, Salvatore. Interesse pubblico e interesse privato nel diritto di proprietà. In: La proprietà nel nuovo diritto, Milano, Giuffrè, p. 2 e 3.

${ }^{3}$ XIFARAS, Mikhail. La Proprieté - Étude de philosophie du droit, Paris, Presses Universitaires de France, 2004. Les théories de la justice - une introduction. Éditions La Découverte, Paris, 1999. HUET, Michel. Le droit de l'urbain - De l'urbanisme à l'urbanité. Paris, Econômica, 1998. PROUDHON, Pierre-Joseph. O que é a propriedade? São Paulo, Martins Fontes, 1988, dentre outros autores que se dedicaram ao assunto.

${ }^{4}$ Trecho da conferência intitulada "Le garanzie pubblicistiche della proprietà: gli aspetti sostanziali", proferida no "VII Congresso Nazionale Giuridico -
“A época na qual vivemos é, certamente, uma época de transição. Assistimos a profundas transformações na total ordem das coisas, um diverso sistema de valores é hoje atribuído às ciências físicas, aos próprios elementos constitutivos do cosmos e, para sermos exatos, tanto aqueles do macrocosmo quanto aqueles do microcosmo.

$\cdots$

Ora, e se há um tema que pode confirmar tudo isso é exatamente aquele da propriedade; não apenas este, mas seguramente é um dos mais significativos."

Situa-se a propriedade, não só num sistema de valores, mas também no constante e turbulento cenário de transições vividas pela civilização.

No percurso histórico, com o intuito de rememorar apenas algumas fases, as de maior relevo, pelas quais se moveu a propriedade, parte-se das Institutas de Justiniano, como produto final das interpolações do Direito Romano Clássico, em que dominava a noção absoluta, simbolizando o poder mais irrestrito e incondicionado que um indivíduo detinha sobre certo objeto, que era o direito de utilizála como melhor lhe aprouvesse, de desfrutá-la e de receber seus frutos. ${ }^{5}$

Forense", sobre "Il diritto di proprietà: attualità e prospettive", Messina -Taormina, de 16 a 1 de setembro de 1983 , p. 541 . Texto original: "L'epoca nella quale stiamo vivendo è, certamente, un'epoca di transizione. Assistiamo a profonde trasformazione nell'intero ordine delle cose, un diverso sistema di valori è oggi attribuito dalle scienze fisiche agli stessi elementi costitutivi dei cosmo e, per essere esatti, sia a quelli dei macrocosmo sia a quelli dei microcosmo... Ora, se vi e un tema che può offrire Ia conferma tutto ciò e proprio quello deI Ia proprietà; non solo questo, ma sicuramente esso è uno di quelli piú significativi”.

${ }^{5}$ Há dissensões doutrinárias a respeito deste caráter absoluto, ilimitado e individual da propriedade em Roma. John Gilissen contrapondo-se à doutrina de Bonfante, afirma que "não se tratava de um poder ilimitado; 
A partir da Alta Idade Média, outro panorama se delineia. Vigia o feudalismo, sistema político assentado na concessão de feudos pelo rei, isto é, direitos de governo sobre as terras a senhores menores, em troca de um contingente militar. Nessa rede de "proprietários", um nobre poderia ser, ao mesmo tempo, vassalo de um senhor e suserano de outro. Arremata Fernando Andrade de Oliveira ${ }^{6}$ que "o resultado é que duas pessoas, o senhor e seu vassalo, tinham ao mesmo tempo e sobre a mesma terra direitos perpétuos de natureza diferente”.

$\mathrm{Na}$ escala do sistema feudal, o objetivo inicial era, sobretudo, de proteção dos senhores e de suas terras. No entanto, com o desenvolvimento e conseqüentes mudanças dos feudos, certos senhores construíram muralhas distanciadas da casa principal, propiciando a moradia dos camponeses e uma estrutura social diversa. ${ }^{7}$ Intimamente ligados à revolução agrícola, dois fatores tiveram relevância no desenvolvimento social da época: renascimento do comércio e, com ele, o ressurgimento e fortalecimento das cidades.

É inegável a influência do revigoramento econômico da Idade Média com o (re)aparecimento das cidades, pois, como

mesmo na Lei da XII Tábuas o poder do proprietário era limitado, sobretudo no que respeita a imóveis, quer no interesse dos vizinhos, quer no interesse público". Ob. cit., p. 638. No mesmo sentido Pedro Escribano Collado, La propiedad privada urbana (encuadramiento y regimen), Madrid, Montecorvo, 1979, p. 25-27

${ }^{6}$ Ob. cit., p. 77.

${ }^{7}$ Oportuna a advertência de Leo Huberman de que "nenhuma descrição do sistema feudal pode ser porque as condições variavam muito de lugar para lugar”. In: História da riqueza do homem. Tradução de Waltensir Dutra, 17.ed., Rio de Janeiro, Zahar, p. 14. bem acentua Henri Pirenne, nenhuma civilização a vida urbana se desenvolveu independentemente do comércio e da indústria. ${ }^{8}$ Burgos, aldeias e vilas tornaram-se independentes, desligando-se do seu antigo senhor feudal, fazendo nascer a "burguesia", formada, em sua maioria, pelos negociantes.

A ingerência de causas econômicas em relação à propriedade e à política vigorantes resta inafastável: a riqueza encontrava-se, preponderantemente, nas mãos dos burgueses e, portanto, era mais conveniente ao senhor feudal a eles se aliar, dando-lhes uma independência controlada. As cidades, por outro lado, passavam a ter outros atrativos, tornando-se o local das manifestações culturais, sociais, políticas e econômicas da coletividade.

A propriedade imóvel adquire, nesse passo, a característica urbana e torna-se também objeto de mercancia: seu comprador detinha o "usus" e o "dominium” sobre a terra.

Deflagrada a decadência do feudalismo nos séculos XIV e XV, contínuos embates se travaram entre nobreza e clero, de um lado, e os burgueses, de outro, e cujo cerne do conflito se situava no uso e na posse da terra e na destinação do solo: os proprietários originários usavam-no com o fim único de cultivo. Todavia, diante da nova situação socioeconômica que brotava na Europa, os burgueses, já possuidores de grande parte das terras, preferiam determinar seu uso à construção de moradias e edifícios destinados à mercancia.

${ }^{8}$ PIRENNE, Henri. As cidades na Idade Média. Tradução de Carlos Montenegro Miguel, 3. ed., Lisboa, publicação Europa -América, 1973, p. 103. 
Esse quadro desencadeou a crescente demarcação do solo voltada à construção: o que antes era terra produtiva, utilizada para a agricultura, passou a ser improdutiva, voltada à ocupação e especulação imobiliária.

Os séculos XVI, XVII e XVIII, em especial, são tidos como a fase transitória do feudalismo para o capitalismo e as cidades, mediante os chamados foros municipais, eram independentes juridicamente, diluindo, ainda mais, o poder político dos nobres.

Os foros municipais, conforme noticia Pedro Escribano Collado, ${ }^{9}$ consistiam no direito urbano em sua essência, e neles, internamente, a propriedade deles oriunda possuía limitações (especialmente do direito de vizinhança), mas se demonstrava livre, plena e única na sua estrutura externa, se comparada com a propriedade fragmentada e limitada do sistema senhorial.

A nobreza, ao perceber a diminuição de seu poderio com o êxodo dos camponeses para as cidades e pela ascendência ininterrupta da burguesia, tem no seu apoio ao soberano o único meio de permanecer com algum poder de decisão. É a passagem para o chamado "Estado Absoluto".

Sobressaía, nesse período, a adoção de uma política centralizadora e o principal instrumento residia na tributação exacerbada das operações mercantis e no confisco dos bens da Igreja. Paulatinamente, a nobreza foi retomando as propriedades e fazendo incidir sobre elas pesados encargos tributários. Este estado de coisas perdurou até o século XVII, quando germina o Iluminismo e o retorno às instituições romanas, como resistência à filosofia do Estado absolutista.

\footnotetext{
${ }^{9}$ COLLADO, Pedro Escribano, ob. cit., p.31.
}

A emancipação do solo realizou-se em duas etapas. Em agosto de 1789, a Assembléia Constituinte aboliu o chamado "feudalismo dominante" (as servidões, justiças, senhorias, banalidades etc.), sem indenização alguma, e proclamou resgatáveis - como decorrência do "feudalismo contratual" - os censos e os direitos casuais de transmissão. Porém, foi a Convenção de julho de 1873 que determinou definitivamente a extinção de todos os direitos antes recuperáveis. ${ }^{10}$ Espelha, essencialmente, a confirmação do deslocamento da propriedade e livra a terra dos encargos que sobre ela pesavam, pois a transferência da propriedade do senhor para o vassalo já era fato consumado antes mesmo da Revolução Francesa.

Comenta Vittorio Scialoja ${ }^{11}$ que, nesse momento, a estrutura da propriedade "é um pequeno reino do qual o proprietário é o soberano; uma soberania de direito privado."

Muito embora persistisse a definição no plano jurídico e ainda atendendo aos moldes do Code Civil, a propriedade sofreu transformações fundamentais especialmente nos séculos XIX e XX.

${ }^{10}$ GILISSEN, John. Ob.cit., p. 648. O sistema da propriedade medieval, em alguns países, perdurou até o século XIX. Na Inglaterra, o feudalismo teve o seu fim decretado somente em 1922 e 1925 ("Real property law”), continuando o regime anglo-saxão dos bens imbuído do espírito medieval.

11 SCIALOJA. Vittorio. Diritto Romano. La proprietà. Lezione compilate daI Dottore Guido Storch, Università di Roma, Associazione Universitaria Romana, 1908/1909, p. 39 a 46. Texto orginal: "è um piccolo regno di cui il proprietario è il sovrano; uma sovranità di diritto privato”. A volta à concepção romana de propriedade firma-se, de modo contundente, com o Code Civil de 1804, que no seu artigo 544, contempla: “La propriété est le droit de jouir et disposer des choses de Ia manière plus absolut". Tradução: "A propriedade é o direito de gozar e dispor das coisas da maneira mais absoluta". 
Foi provocadora de males e de ódios, como afirmou Proudhon: "A propriedade éo roubo", ou ainda, no "Manifesto Comunista" de 1948, Engels e Marx declararam que era necessário "abolir a propriedade burguesa", mas com a supressão apenas da propriedade dos meios de produção e não de toda a propriedade privada.

O predomínio do subjetivismo e do individualismocontrastavacomos movimentos coletivos, ao lado do desenvolvimento tecnológico e industrial que permitiu revelar outras formas de propriedade.

Houve, então, uma expansão do conceito de propriedade. Exemplo disso é o fato de que certos bens que não podiam ser objeto de propriedade passaram a sê-lo, como as patentes de invenção, obras artísticas e literárias, dando nascimento à propriedade artística, literária, industrial.

Pedro Escribano Collado ${ }^{12}$ alerta que, mesmo no período pós-revolucionário francês, a propriedade privada e o Direito público não se contrapunham. Os princípios que informaram a Revolução Francesa e a "Declaração dos Direitos do Homem e do Cidadão", em 1789, plasmaram todo o sistema jurídico. O regime jurídico da propriedade privada, em dada medida e por

${ }^{12}$ Pedro Escribano Collado ressalta que "es posible, pues, constatar el peso especifico que en el régimen jurídico de la propiedad privada ha tenido desde la revolución francesa el Derecho público, como catalizador de las corrientes socio-económicas dominantes en cada momento histórico en la sociedad.... Durante un período dilatado de tiempo va a existir una plena correspondencia entre Derecho público y propiedad privada, no obstante los instrumentos jurídicos por medio de los cuales se pretendió corregir, unas veces, y delimitar, otras, el contenido del derecho". Ob. cit., p. 66. longo tempo, entrelaçaram-se, em maior ou menor intensidade, a depender do contorno limitador dado à propriedade e ao direito de propriedade.

A subjetividade do direito que, de um lado, parece residir na própria existência da propriedade; de outro, a transferência da disponibilidade dos bens por parte do indivíduo à coletividade, ou ao Estado, confirma a existência de uma propriedade diferente, voltada para o interesse público.

\subsection{A função social da propriedade e o trato constitucional.}

Revela firme na contemporaneidade, o entendimento de que a propriedade privada não mais se funda, com exclusividade, sobre o individual. Sob todos os aspectos, a propriedade privada deve estar orientada de modo a proporcionar a mais idônea tutela dos interesses coletivos.

A Constituição da República de 1988 assegura o direito de propriedade, manifestando uma escolha fundamental do constituinte. ${ }^{13}$ Torna intocável a existência do instituto da propriedade privada, especialmente no sentido de que não é permitido ao legislador ordinário eliminá-lo. ${ }^{14}$ Garante a propriedade ao incluí-lo dentre os direitos e

${ }^{13}$ A Constituição Federal de 1988 tem este princípio expresso no artigo $5^{\circ}$ inciso, XXII, inserto no Capítulo "Dos Direitos e Garantias Individuais e Coletivos", que estabelece: "é garantido do direito de propriedade".

${ }^{14}$ Nesse sentido, no direito italiano, Stefano Rodotà, reportado por Iannelli, Antonio. La proprietà costituzionale. Camerino, Edizione Scientifiche Italiane, 1980, p. 142. Posição também firmada no direito alemão segundo Fritz Baur. O desenvolvimento de proteção ao direito de propriedade na República Federal da Alemanha. In: Revista Forense, Rio de Janeiro, Forense, 1983, n. 281, p. 133-139. 
as garantias fundamentais e o faz na medida em esta deve cumprir sua função social, ${ }^{15}$ mas igualmente insere como princípios da atividade econômica. ${ }^{16}$

Diante da dicção constitucional, José Afonso da Silva infere que a propriedade privada, no Brasil, definitivamente, adquire contornos novos, com conceito e significados relativos, pois também consta como um dos princípios da ordem econômica que tem como fim "assegurar a todos existência digna, conforme os ditames da justiça social". ${ }^{17}$

Ao analisar a propriedade conforme disciplinada na Constituição italiana vigente e que também elege a função social como princípio constitucional, ${ }^{18}$ Antonio Iannelli ${ }^{19}$ anota que não há sentido em considerar o interesse público como algo divorciado da estrutura do direito de propriedade que o limita externamente. E conclui que “Ao contrário, tanto a propriedade privada ou publica tem razão de ser somente (e enquanto) corresponde aos interesses de toda a comunidade”.

${ }^{15}$ Artigo $5^{\circ}$, inciso XXIII, da Constituição da República de 1988, prevê: "a propriedade atenderá a sua função social”.

${ }^{16}$ Artigo 170, incisos II e III, da Constituição da República vigente, determinam, respectivamente: "A ordem econômica, fundada na valorização do trabalho humano e na livre iniciativa, tem por fim assegurar a todos a existência digna, conforme os ditames da justiça social, observados os seguintes princípios: II- propriedade privada; III função social da propriedade".

${ }^{17}$ SILVA, José Afonso. Curso de Direito Constitucional Positivo, 23.ed., São Paulo, Malheiros, 2004, p. 281.

${ }^{18}$ Artigo 42, da Constituição italiana: "La proprietà è pubblica o privata”. Tradução livre: “A propriedade é pública ou privada".

${ }^{19}$ IANNELLI, Antonio, ob. cit. p. 148.Texto original: “Al contrario, la proprietà privata o pubblica che sia ha raggione d'essere solo se (e per quanto) riscontra interessi dell 'intera comunità".
Numa posição conciliadora, Salvatore Pugliatti $^{20}$ elabora um mecanismo cujo propósitoé a harmonia entre esses extremos: ao lado do interesse privado se coloca o interesse público, em que se percebe a necessidade de criar e aplicar um complexo de instrumentos que possam garantir, mediante o exercício do direito privado, a tutela do interesse público. $\mathrm{E}$, para tanto, há exigências que devem ser satisfeitas, como abolir o confronto entre o público e o privado, de modo a que este não constitua óbice àquele, encontrando o equilíbrio entre eles e dosando o instrumental usado na execução dos fins, para que o sacrifício do particular seja equivalente ao benefício do coletivo. E, nas palavras de Manoel de Oliveira Franco Sobrinho, ${ }^{21}$ compete ao Estado "tutelar direitos...Cabe, sim, respeitá-los. Há, portanto, interesses a conciliar. $O$ interesse que é 'público' com o interesse que é 'privado'. Os direitos dos dois lados".

Em suma, os princípios norteadores da propriedade privada devem estar voltados à possibilidade de cada indivíduo contribuir, na medida de sua condição e de seu poder de proprietário, para a concretização do interesse público e do atendimento das necessidades que se anunciam prementes em dada sociedade.

Assinalam Pedro Collado ${ }^{22}$ e Stefano Rodotà $^{23}$ que a função social tem o papel

${ }^{20}$ Neste sentido Salvatore Pugliatti. Interesse pubblico e privato nel diritto di proprietà. In: La proprietà nel nuovo diritto. Milano, Giuffre, 1964, p. 36 e ss.

${ }^{21}$ OLIVEIRA FRANCO SOBRINHO, Manoel de. Desapropriação. 2.ed., São Paulo, Editora Resenha Universitária, 1977, p. 27.

${ }^{22}$ ESCRIBANO COLLADO, Pedro. Ob. cit, p. 118.

${ }^{23}$ RODOTÀ, Stefano. Proprietà (diritto vigente). In: Novissimo Digesto Italiano, Torino, UTET, 1976, p. 129. 
determinante de alterar a estrutura tradicional do direito de propriedade a partir da opção legislativa de incluir, no ordenamento jurídico, preceitos que dirijam o seu exercício, não apenas à satisfação de interesses privados mas, preponderantemente, das exigências da sociedade como um todo.

Subjacente a toda essa construção, há a preocupação em dosar ponderadamente o interesse da coletividade organizada e o dos sujeitos que a compõem, advindo de uma complexa relação entre o Estado e os cidadãos. É a análise das relações entre o fechado interesse privado no esquema clássico do direito de propriedade e o interesse público, que constitui a mola propulsora das normas que atacaram o invólucro protetor do interesse privado.

Apresentam-se, então, dois aparentes extremos: o interesse público e o interesse privado e, sobre eles, imposta-se o equilíbrio social. Porém, o direito de propriedade, o interesse público e o interesse privado podem, de diversos modos, aproximar-se e se entrelaçar. Existe uma razão de contato situada exatamente naquela relação: se o direito de propriedade - como direito subjetivo - é o reconhecimento e a proteção de um interesse privado; ao interesse público são deixados os limites, os termos e os modos de reconhecimento e proteção, consubstanciados nas normas de Direito Público.

$\mathrm{O}$ direito de propriedade - nas suas várias manifestações - deve produzir a harmonia entre o interesse público e o interesse privado, que não se excluem necessariamente e admitem essa solução de compromisso.

Esse resultado contemporâneo tem, na eclosão da Primeira Grande Guerra, o início de graves e perseverantes mudanças. Há forte e irreversível intervenção do Estado na distribuição dos bens, almejando a satisfação de certas necessidades sociais em virtude dos efeitos funestos da Guerra. Germina, pois, uma concepção que permeia o Direito e perdura até nossos dias: a "função social da propriedade". ${ }^{24}$

$\mathrm{Na}$ esteira evolucionista, Luiz Edson Fachin $^{25}$ expõe o ponto decisivo para o surgimento da doutrina da função social da propriedade, reportando-se à lição de Eduardo Espíndola, na qual fica demonstrada que a doutrina da função social da propriedade teve seu marco originário já na Constituição de Weimar, de 1919, contendo o princípio de que "a propriedade obriga" e que foi acolhida pelas demais legislações da época.

É oportuno mencionar a divergência doutrinária no que tange ao campo de projeção da função social.

Para alguns, a função social reside no seu uso da propriedade, atingindo o seu exercício. Nessa linha de raciocínio, defende Luiz Edson Fachin ${ }^{26}$ que "a doutrina da função social da propriedade corresponde a uma alteração conceitual do regime tradicional; não é, todavia, questão de essência, mas sim pertinente a uma parcela da propriedade que é a sua utilização".

Outros entendem que a função social é amalgamada à essência da propriedade: ela é, em si mesma, função social.

${ }^{24}$ Ao lado da função social da propriedade, a construção da teoria do abuso de direito, cada uma atuando em sentidos diferentes, contribuíram para uma nova configuração do Direito Público. Ibidem, p. 67.

${ }^{25}$ FACHIN, Luiz Edson. A função social da posse e propriedade contemporânea (uma perspectiva da usucapião imobiliária rural), Porto Alegre, Sérgio Antonio Fabris Editor, 1988, p. 17.

${ }^{26}$ Ibidem, p. 18. 
Com exatidão, Salvatore Pugliatti, ${ }^{27}$ propõe-se a refletir se "para completar a análise da definição legal da propriedade é necessário examinar a questão mais comum que hoje se põe em relação ao conceito da propriedade: se ela deve ser entendida como função social, ou se tem uma função social".

Contribuições no sentido da presença funcional da propriedade não faltaram na doutrina nacional e estrangeira. ${ }^{28}$

A estrutura do direito de propriedade é estudada por Gustavo Tepedino ${ }^{29}$ e o faz sob duas óticas: a estrutural e a funcional. $\mathrm{O}$ aspecto estrutural forma-se pelo elemento interno é constituído pelas faculdades de usar, gozar e dispor (econômico) e pelo elemento externo (alijar de influências alheias); o aspecto funcional, ou dinâmico, traduz-se no modo pelo qual flui e influi no mundo dos

${ }^{27}$ PUGLIATTI, Salvatore. Definizione della proprietà nel Codice Civile. In: La proprietà nel nuovo diritto, ristampa, Milano, Giuffre, 1964, p. 141. Texto original: “a completare l'analisi de Ia definizione legale deIIa proprietà è necessario examinare Ia più comun questione che oggi viene posta in relazione al concetto della proprietà: se essa, cioè, debba intendersi come funzione sociale, o se essa abbia una funzione sociale”.

${ }^{28}$ Léon Duguit encontrava a própria razão se ser dos direitos na medida em que devem desempenhar uma função, influindo e construindo a sociedade. Traité de Droit Constitutionel, tomo 3. Franz WIEACKER revela as consequiências trazidas, pela Primeira Grande Guerra, à liberdade contratual e à liberdade de utilização da propriedade. História do Direito Privado Moderno, tradução de ${ }^{a}$ M. Botelho Hespanha, 2.ed., Lisboa, Calouste Gulbenkian, 1993, p. 631 e 632. Orlando GOMES, Direitos Reais, 10. ed., Rio de Janeiro, Forense, 1988. Gustavo TEPEDINO, A nova propriedade (e sei conteúdo mínimo entre o Código Civil, a legislação ordinária e a Constituição), Revista Forense, volume 306, 1989, dentre outros.

${ }^{29}$ TEPEDINO, Gustavo. Aspectos da propriedade privada na ordem constitucional, In: Estudos Jurídicos, editada pelo Instituto de Estudos Jurídicos, Rio de Janeiro, 1991, p.314. fatos e qual influência opera a propriedade na sociedade e nas suas relações.

A tendência, frise-se como incessante, é a reformulação de $\operatorname{conceitos}^{30}$ na qual direito de propriedade individual se volta para um escopo mais humanista, enfatizando sua sujeição aos interesses da comunidade, valorizando a liberdade e a dignidade de cada indivíduo aliada à solidariedade, e apoiada a harmonia entre a propriedade individual e os interesses da coletividade. ${ }^{31}$

\subsection{A função social da propriedade urbana}

Recortando-se na propriedade urbana, um dos prismas sob os quais é possível vislumbrá-la, a função social "é resultado da projeção da atividade humana, que está impregnada de valor cultural, no sentido de algo construído pela projeção do espírito do homem".32

Na observação de Pedro Escribano Collado, ${ }^{33}$ a função social da propriedade urbana apóia-se no pressuposto de que da atividade urbanística constitui-se em uma função pública da Administração e, em virtude disso, tem ela o poder de determinar a ordenação urbanística das cidades, atingindo, direta ou indiretamente,

${ }^{30}$ ELUSTIZA, Angel Sustaeta. Propiedad y urbanismo, Madrid, Montecorvo, 1973, p. 45.

${ }^{31}$ Obras fundamentais sobre o assunto, dentre muitas, cite-se LEAL, Rogério Gesta.Direito Urbanístico - Condições e possibilidades da Constituição do Espaço Urbano, Rio de Janeiro, Renovar, 2003 e LIRA, Ricardo Pereira. Elementos de Direito Urbanístico. Rio de janeiro, Renovar, 1997.

32 SILVA, José Afonso da. Direito urbanístico brasileiro, 3.ed. revista e atualizada, São Paulo, Malheiros, 2000, p. 74.

${ }^{33}$ Ob.cit., p.137. 
os direitos patrimoniais privados e até a sua iniciativa.

A determinação do direito de propriedade urbana, sempre atada à funcionalidade que deve desempenhar, é o fruto dos planos de ordenação urbana, sejam gerais - no caso dos planos diretores -, ou especiais - como os planos de zoneamento, de implantação de distrito industrial, de renovação urbana, de loteamento e de outros procedimentos e normas legais urbanísticas -, que possibilitam a qualificação urbanística para cada parcela do terreno, especificando-se, deste modo, o conteúdo e o exercício do direito de propriedade.

A qualificação urbanística submete o direito do proprietário do solo conforme as perspectivas de desenvolvimento da cidade, ${ }^{34}$ previstas no plano urbanístico,

Esboça-se o regime jurídico da propriedade urbana fundado no princípio da função social, pois o direito de propriedade, voltado ao urbanismo, é invariavelmente influenciado por motivos de ordem social, acolhendo no seu âmago, "interesses privados de seu titular e interesses públicos e sociais", ${ }^{35}$ que se consubstanciam no planejamento urbano e nos planos urbanísticos.

Portanto, o plano urbanístico que, grosso modo, projeta a qualificação a ser dada ao solo em dado espaço e tempo, deve ser

${ }^{34}$ Sustenta Pedro Escribano Collado que "el derecho del propietario está sometido a un presuposto de hecho, la calificación urbanística de los terrenos, cuya fijación es competencia de la Administración, de naturaleza variable, de acuerdo con las necessidades de desarollo urbanístico de las ciudades, cuya apreciación corresponde asimismo a la Administración”. Ob.cit., p. 138.

35 Ibidem, p. 185. Texto original: “interesses privativos de su titular e interesses públicos y sociales”. norteado pela função que lhes é ínsita e acompanhar a dinamicidade das metamorfoses ensejadas pelas cidades, com seus múltiplos interesses, atendendo aos princípios que cada ordenamento jurídico contempla, explícita ou implicitamente.

\section{O URBANISMO E O SURGIMENTO DO DIREITO URBANÍSTICO}

Aponta, a doutrina, ${ }^{36}$ a relação existente entre urbanização, urbanismo e direito urbanístico e, sobretudo, aquele como objeto deste.

Sem dúvida, urbanismo e direito urbanístico são realidades indissociáveis, que se sobrepõem, na medida em que não é razoável qualquer abordagem de direito urbanístico sem aludir às noções de urbanismo e, principalmente, à sua operacionalidade mediante a urbanização e à atividade urbanística. ${ }^{37}$

Eduardo García de Enterría e Luciano Parejo Alfonso ${ }^{38}$ demonstram a causa do

${ }^{36}$ FERNANDEZ, Antonio Carceller. Instituciones de derecho urbanístico. Madrid, Montecorvo, 1979, p. 33; WOLFF, Joseff. EI planteamiento urbanístico deI territorio y Ias normas que garantizan su efectividad conforme a la ley federal de ordenación urbanística y los municipios. Madrid, Instituto de Estudios de Ia Administración Local, 1973, p. 12; SILVA, José Afonso da. Direito urbanístico, p. 26 a 34, dentre outros.

${ }^{37}$ José Afonso da Silva define "atividade urbanística" como a "ação destinada a realizar os fins do urbanismo, ação destinada a aplicar os princípios do urbanismo", In: Direito Urbanístico, p. 15.

38 “...el urbanismo es un fenómeno colectivo que, por una parte impone ciertos métodos públicos de actuación por parte de las organizaciones políticas y, por otra, incide sobre las situaciones jurídicas de los ciudadanos, en medida, por cierto, extraordinariamente relevante. Por una y otra de estas dos razones estructurales el urbanismo se expressa necesariamente en una ordenación jurídica, a la que podemos distinguir con el nombre convencional 
entrelaçamento entre o urbanismo e direito urbanístico, como instituições inseparáveis,

O urbanismo pode ser expresso de modo breve, porém abrangente, como ciência, arte e também como técnica da organização espacial dos estabelecimentos humanos. ${ }^{39}$

Ao longo da história, as cidades e os povoados foram se formando e crescendo sem que se ativessem a qualquer planejamento urbano efetivo. A cidade não era vista na sua totalidade, de modo a exigir uma ordenação e um planejamento, não levando em conta as muitas circunstâncias que constituem a vida dos habitantes, como espaços destinados ao lazer, ao comércio, à indústria, à prestação de serviços públicos, infra-estrutura. A iniciativa estatal era minguada e reduzia-se à regulamentação de salubridade, altura dos edifícios e traçado das vias públicas. O desenvolvimento das cidades deu-se, então, pela multiplicação de certos projetos particulares de edificação e direcionavam-se à satisfação das necessidades específicas de cada um dos particulares. Logo, inexistia qualquer planejamento.

Exsurge, apropriada e emergencialmente, a imprescindibilidade do urbanismo que, segundo Joseff Wolff, ${ }^{40}$ tomado sob uma

de Derecho urbanístico". GARCÍA DE ENTERRÍA, Eduardo e PAREJO ALFONSO, Luciano. Lecciones de derecho urbanístico. Madrid, Civitas, 1981, p. 65.

${ }^{39}$ Etimologicamente, a palavra "urbanismo" deriva do termo latino "urbs", que significa "cidade" e, por extensão, relaciona-se também às pessoas que nela habitam. Pierre MERLIN e Françoise CHOAY, ao comparar "urbano" e "urbanidade", "urbanismo" "est alternativement défini comme Sicence, Art et/ou Technique de l'organization spatiale des établissements humains". In: Dictionnaire de lúbrnaime et de l'Aménagement, Paris, PUF, 1996.

${ }^{40}$ WOLFF, Joseff. WOLFF, Joseff. EI planteamiento urbanístico deI territorio yIas normas que garantizan visão mais moderna, não se volta apenas à idealização de novos traçados para cidades, povoados ou determinados setores preexistentes mas, sobretudo, "a ação voltada a processar a sua evolução e as alterações que experimentam como conseqüiências das novas edificações e demais construções e instalações que surgem no dia a dia”.

Precedeu a esse novo conceito de urbanismo a denominada posição tradicional que consistia, basicamente, na arte de ordenar a cidade ou, ainda, como planificação urbana local. Surge corrente mais avançada tendente a distinguir "urbanismo" e "ordenação do território". ${ }^{41}$

Considerando-se a evolução e organização sociais intensas, incessantes e aceleradas, o urbanismo deixou de ser simples instrumento ordenador das cidades para tornar-se um meio de adequação das pessoas que nela vivem, voltado para a planificação estrutural demográfica, social e econômica em uma dada parcela do solo. ${ }^{42}$

su efectividad conforme a la ley federal de ordenación urbanística y los municipios. Madrid, Instituto de Estudios de Ia Administración Local, 1973, p. 14, texto original: "Ia acción encaminada a encauzar su evolución y Ias alteraciones que experimentan como consecuencia de Ias nuevas edificaciones y demás construcciones e instalaciones que surgen día a día”.

${ }^{41}$ Posição adotada por JACQUIGNON, Louis. Droit de l'urbanisme. Paris, Éditions Eyrolles, 1975, p. 2:"l'urbanisme se définit comme l'art de concevoir l'aménagement des villes sur des données démographiques, économiques, esthétiques et culturelles, en vue de bien-être humain e de la protection de l'environnement".

${ }^{42}$ LOPES MEIRELLES, Hely. Direito municipal brasileiro. 3. ed., São Paulo, R.T., 1977, p. 591 e WOLFF, Joseff. p. 13. Nota-se referências feitas por autores que incluem no âmbito de atuação do urbanismo todos os espaços habitáveis, ou seja, tanto na cidade quanto no campo. 
Antonio Carceller Fernandez ${ }^{43}$ define urbanismo, ressaltando sua abrangência e importância, considerando-o "o conjunto de conhecimentos que se referem ao estudo para a criação, desenvolvimento, reforma e progresso dos povoados conforme a ordem das necessidades materiais da vida humana”.

A doutrina francesa, capitaneada por Marcel Waline, ${ }^{44}$ entende que se o urbanismo não é uma técnica de definição de ordenação do solo, deve levar em conta como referencial, que certos fatos são conseqüências da ordenação. Trata-se de uma compreensão mais restrita de urbanismo, tratando-o como instrumento operacional para a ordenação do território.

Já a doutrina italiana, comungada por Federico Spantigati, ${ }^{45}$ embora partindo de um sentido limitado de urbanismo, evolui e acaba por equipará-lo a uma ciência: a ciência do território.

José Afonso da Silva parece concordar com este posicionamento ao anotar que "como técnica e ciência interdisciplinar que é, o urbanismo correlaciona-se com a cidade industrial, como instrumento de correção dos desequilíbrios urbanos, nascidos da urbanização e agravados com a chamada explosão urbana dos nossos dias" ${ }^{46}$

${ }^{43}$ Ob. cit.,, p. 33. Texto original: "el conjunto de conocimientos que se refieren aI estudio de Ia creación, desarrolo, reforma y progreso de los pobIados en orden a Ias necesidades materiales de Ia vida humana".

${ }^{44}$ Posição trazida por Antonio Carceller Fernandez, p. 36, mediante uma abordagem do direito comparado francês, italiano e espanhol.

${ }^{45}$ SPANTIGATI, Federico. Manuale di diritto urbanístico. Milano, Giuffre, 1969, p. 47.

${ }^{46}$ SILVA, José Afonso da., p. 27 e 28 . Tal posição é partilhada por Angel Sustaeta Elustiza. Ob.cit.,. 24; NUÑEZ RUIZ, Miguel Angel. Derecho urbanístico español, Madrid, Montecorvo, 1967, p. 19 e 20; MARTINEZ, Jose Luis Laso. Derecho urbanístico. Tomo I, Madrid, Montecorvo, 1981, p. 21.
Na doutrina espanhola, parece ser melhor aceito o primado de amplo urbanismo, cogitada por alguns,${ }^{47}$ como "macrourbanismo", diferenciando-o das técnicas de "ordenação do solo", que possuem um caráter predominante político, e técnicas de "ordenação da cidade", de cunho jurídico, como o zoneamento, que desempenha papel relevante na atividade urbanística.

Há, pois, uma multiplicidade de posicionamentos a respeito da concepção de urbanismo. Não há como desconsiderar que cada corrente se encontra afinada às modificações históricas, sociais, políticas, econômicas e jurídicas de realidade. Uns, com concepções mais restritas; outros, mais largas, contudo, há a convergência de pensamento de que é a função do urbanismo o planejar a cidade, globalmente considerada, com vistas à melhoria de qualidade de vida dos indivíduos que a habitam. Com clareza, Angel Sustaeta Elustiza ${ }^{48}$ ensina que “...o sociológico serve-lhe de base, temperado por uma adequada planificação de estruturas que integre o socioeconômico do viver humano em relação ao bem-estar do indivíduo e da coletividade. Bem-estar que, por sua vez, traz em si a exigência de uma cada vez maior de

${ }^{47}$ Como é o caso de Eduardo GARCÍA DE ENTERRÍA, trazido por Antonio FERNANDEZ, Antonio Carceller. Ob. cit., p. 35.

${ }^{48}$ ELUSTIZA, Angel Sustaeta., p. 29. Trecho original: “...lo sociologico le sirve de base, temperado por una debida planificación de estructuras que integre lo socio-economico del vivir humano en orden al bienestar del individuo y por ende la colectividad. Bienestar social que, a su vez, lleva en sí la exigencia de una cada vez. mayor imitación de la libertad individual, precio que es necesario satisfacer en mayor o menor grado para que dicha convivencia sea eficaz y duradera". 
limitação da liberdade individual, esforço que é necessário satisfazer em maior ou menor grau para que essa convivência seja eficaz e duradoura".

Em última análise, o urbanismo é uma realidade, um "fato" retratado pelas persistentes exigências dos assentamentos urbanos, pela progressiva necessidade de ordenação e aproveitamento do solo. Ao lado desta realidade social invencível, o urbanismo é, igualmente, um desafio, na medida em que dele partem novas expectativas de utilização do solo, de melhoria de vida dos aglomerados humanos, de racionalização do espaço e do uso do meio ambiente.

O urbanismo, concebido como técnica de criação e desenvolvimento das cidades, possui características intimamente relacionadas com a vida da sociedade amplamente considerada, ao lado do indivíduo, singularmente valorado, e que o Estado não pode permanecer indiferente.

Há, potencialmente, interesses que se contrapõem: o interesse do particular e o da coletividade. É, pois, o direito de propriedade, situado entre o público e o privado, gerando tensões e marcantes desumanidades. ${ }^{49}$

Nesse confronto inevitável, dá-se a recepção deste fato $^{50}$ pelo Direito. Ou seja,

${ }^{49}$ Sobre a igualdade do planejamento e da desigualdade da ocupação do solo, ver CORREIA, Fernando Alves. O plano urbanístico e ao princípio da igualdade, Coleção Teses, Coimbra, Almedina, 1989; CHAUVIN, Nicolas. L'illegalité du Plan d'Occupation des Sols, Paris, LITEC, 1996.

${ }^{50} \mathrm{O}$ "fato urbano" é circunstância reveladora de uma realidade social. Este processo se realiza mediante dupla função do direito urbanístico. Em primeiro lugar, regulamenta juridicamente os fenômenos urbanísticos; em segundo submete a atividade urbanística do Poder Público e dos particulares ao Direito, forma e regula certas instituições, como é o caso do direito de propriedade. Fornece instrumentos ao Poder Público o Estado, mediante o processo legislativo, passa a intervir incisivamente na ordenação do crescimento social e, conseqüentemente, participa do processo urbano: desde o incentivo para a edificação à ordenação do solo.

para a realização da ordenação do solo e das cidades, procurando a realização do interesse público, limitando a liberdade individual, porém sem eliminar o interesse privado. A doutrina, baseada na verificação dos fenômenos que compõem o urbanismo, tenta formular definições para este ramo Direito.

No Brasil, José Afonso da SILVA leciona que o direito urbanístico "forma-se de um conjunto de normas que ainda pertencem a várias instituições jurídicas, parecendo mais adequado considerá-lo, em seu estágio atual, como uma 'disciplina de síntese' ou 'ramo, interdisciplinar' do Direito que, aos poucos, vai configurando suas próprias instituições”. E complementa que as normas sintetizadas pelo direito urbanístico são de direito público. Ob cit., p. 43. Já Louis JACQUIGNON define o direito urbanístico "comme I 'ensemble de regles à travers lesquelles Ia collectivité, au nom de l'utilité publique, et les titulaires de droits de propriété, au nom de Ia défense des intérêtes privés, doivent coordonner Ieurs position et action respectives en vie de I'aménagement de Ia cité”. Ob. cit., p. 13. É interessante este conceito de direito urbanístico por levar em conta, de um lado, noções gerais como segurança, salubridade, finalidades sociais genéricas, que devem ser tutelados pelo Poder Público; de outro, a posição de interesses privados que não podem ser relegados.

Com visão diferente, estribada sobretudo no ordenamento jurídico espanhol, Antonio Carceller Fernandez define o direito urbanístico como "el conjunto de normas juridicas que estructuran una rama de Ia administración pública, y, por si mismas o a través deI planeamiento que regulan, definen el contenido de Ia propiedad según su calificación urbanistica y disciplinan Ia actividad administrativa encaminhada a Ia urbanización y Ia edificación”. Ob. cit., p. 31.

Trata-se de um conceito baseado no conteúdo da legislação e que se atém a dois pontos fundamentais: a atuação da Administração Pública e o regime do solo. Há, em todos os conceitos transcritos, embora enfocados de modos variados, visíveis interseções: a presença da Administração Pública que, atendendo ao princípio da legalidade, intervém na propriedade privada dando-lhe uma destinação voltada ao interesse público, apegandose ao conjunto de normas urbanísticas editadas, especialmente, através do plano urbanístico. 
O urbanismo contemporâneo deve estar a serviço do ser humano e na peculiar situação de habitantes de uma dada cidade. ${ }^{51}$

\subsection{A política urbana na Constituição da República de 1988 e na legislação infraconstitucional: os instrumentos de política urbana.}

O Direito Urbanístico, no Brasil, é disciplina de construção recente, e por também as Constituições anteriores não continham disposições sobre o assunto. Não havia preocupação com o urbanismo, qualquer que fosse o alcance de sua acepção: estético, ordenador do solo, planejamento das vilas ou a mais básica, infra-estrutura para prestação dos serviços públicos. Isso se justifica pela absoluta desnecessidade de atentar para esses fatos àquela época: a população era reduzida e o espaço sem limitações.

$\mathrm{Na}$ Constituição do Império, há no artigo 179, inciso XXII, a garantia do direito de propriedade e a previsão de indenização se o interesse público exigisse o uso do bem do particular. Por outro lado, uma menção superficial à administração das províncias determinava que os Conselhos deliberassem sobre os "negócios mais interessarem-se das Províncias; formando projectos peculiares, e accommodados ás suas localidades, e urgencias" (art. 82). Porém, nenhuma referência existe à situação urbana propriamente dita.

51 JACQUOT, Henri e PRIET François. Droit de 1' urbanisme., Paris, Dalloz, 2001, p. 4 Ressaltam os autores que se em certos tempos a organização dos povoados se dava por razões religiosas ou políticas, o urbanismo contemporâneo "se veut somente a serviço dos habitantes da cidade”.(tradução livre).
A Constituição de 1891, dentro da “Declaração de Direitos", art. 72, elege o direito de propriedade plena, ressalvados os casos de desapropriação por necessidade ou utilidade pública, mediante indenização. E, da mesma maneira que sua antecessora, não faz alusão a questões de ordem urbana ou, ao menos, municipais.

Tanto a Constituição de 1934 como a de 1937 também se dirigem apenas ao direito de propriedade e os casos de desapropriação. A possibilidade de constar qualquer menção à propriedade urbana é desprezada.

A Constituição de 1946 é a que dá mais ênfase ao município, à sua autonomia e à administração do seu peculiar interesse. Quanto ao direito de propriedade, também plenamente assegurado, inova apenas com mais uma hipótese de desapropriação que é por interesse social, enquanto o seu fica condicionado ao bem-estar social. E referese, no artigo 147, final, que "a lei poderá..., promover a justa distribuição da propriedade com igual oportunidade para todos". Demonstra essa Carta uma concepção mais livre e abrangente de propriedade, até mesmo pela introdução da Emenda Constitucional ${ }^{\circ}$ 10, de 1964, que acrescentou a hipótese de desapropriação de propriedade rural, para fins de reforma agrária. Ressalte-se, entretanto, que nenhuma referência é feita à propriedade destinada a fins urbanísticos.

A Constituição de 1969 introduziu a chamada "função social da propriedade", no artigo 160, inciso III, ao dispor sobre " $D a$ ordem Econômica e Social”, mas nenhuma preocupação é demonstrada em relação à propriedade urbana e seu desempenho diante da função social, eleito, então, princípio constitucional. 
A inovação de contemplar a matéria relativa à propriedade privada urbana, na seara constitucional, surge, desde logo, com a formação da Subcomissão da questão urbana e transporte", na Assembléia Nacional Constituinte, instalada em 1987. ${ }^{52}$

Toma relevo a preocupação com a denominada "propriedade urbanística", caracterizada pela descoberta de que o contexto em que está inserida extrapola, em muito, o interesse privado do seu titular, idéia originada do conjunto dado pelo plano urbanístico. ${ }^{53}$

Dos debates entre constituintes e representantes da sociedade, surgiu a proposta, incondicional, da "utilização socialmente adequada" ${ }^{54}$ da propriedade imobiliária urbana. Os artigos 182 e 183, sob a rubrica de "Da Política Urbana", denotam o avanço inédito, na esfera constitucional, quanto ao direito de propriedade.

Aliado ao fato de direcionar-se à disciplina de questões urbanas e exigir a ordenação do "pleno desenvolvimento das funções sociais da cidade" e "garantir o bem-estar de seus habitantes”, a Constituição da República de

${ }^{52}$ É de se noticiar que havia, já em 1983, o Projeto de Lei $.^{\circ} 775 / 83$, que buscava regulamentar o uso do solo urbano e o seu controle.

${ }^{53}$ Em nosso sistema legislativo, há o plano urbanístico federal, o plano urbanístico nacional, os planos urbanísticos macrorregionais, federais setoriais, estaduais e municipais, neste último o plano diretor é o instrumento fundamental da política urbana na esfera municipal.

54 Assembléia Nacional Constituinte. Atas das Comissões. Ata da 12a. Reunião Ordinária da Subcomissão da Questão Urbana e Transporte. Diário da Assembléia Nacional Constituinte, suplemento $\mathrm{n}^{\circ}$. 101, da quarta-feira, 22 de julho de 1987, Brasília, 1987, p. 33. De toda a discussão segue-se o texto constitucional aprovado em $1^{\circ}$ Turno, e que persistiu na votação do $2^{\circ}$ Turno.
1988 traz à baila institutos novos e de vasta repercussão no direito em análise. É o caso da edificação e parcelamento compulsórios, da obrigatoriedade do plano diretor para cidades com mais de vinte mil habitantes, qualificando-o como instrumento básico da política de desenvolvimento e de expansão urbana, e que o cumprimento das funções sociais da cidade depende do atendimento "às exigências fundamentais de ordenação da cidade" nele contidas.

O artigo 182, incisos e parágrafos, da Constituição Federal de 1988, remete à lei a regulamentação da política urbana. ${ }^{55}$ O Congresso Nacional, atendendo a tal comando, elaborou alguns projetos de lei ${ }^{56}$ que tramitaram, por longo tempo, até a edição da Lei n. ${ }^{\circ}$ 10.257, de 10 de julho de 2001, oriunda do Projeto de Lei n. ${ }^{\circ}$ 181/89 denominada "Estatuto da Cidade", de autoria do ex-Senador Pompeu de Souza.

${ }^{55}$ Art. 182. "A política de desenvolvimento urbano, executada pelo Poder Público municipal, conforme diretrizes gerais fixadas em lei tem por objetivo ordenar o pleno desenvolvimento das funções sociais da cidade e garantir o bem- estar de seus habitantes."(grifo nosso)

${ }^{56}$ Cite-se os seguintes Projetos de Lei: o Projeto de Lei n. 2191/89, de iniciativa do Deputado Raul FERRAZ, arrolando os "Instrumentos de Desenvolvimento Urbano". O Projeto de Lei n. ${ }^{\circ} 2587.89$, do Deputado Uldurico PINTO, dispõe sobre a matéria de forma muito assemelhada ao projeto anterior; Projeto de Lei, n. ${ }^{\circ}$ 2937/89, do Deputado José Luiz MAlA, é menos detalhado e não tem o alcance que detêm os anteriores. Ainda de iniciativa da Câmara dos Deputados, o Projeto de Lei n. ${ }^{\circ} 4.004 / 89$, da Deputada Lurdinha SAVIGNON, embora bastante abrangente, em pouco se afasta do Projeto n. ${ }^{\circ}$ 2191/89. Há, ainda, o Projeto de Lei n. ${ }^{\circ} 4.024 / 89$, de autoria do Deputado Antonio BRITO, que "dispõe sobre a promoção, a política e o Conselho Nacional de Desenvolvimento Urbano e cria o Sistema Nacional de Desenvolvimento Urbano", traçando normas genéricas sobre a estrutura dos órgãos destinados a efetuar a política urbana; não cuida da matéria em exame. 
Aprovado o Projeto do "Estatuto da Cidade" após 11 anos de tramitação, com várias modificações estruturais e conceituais, define, no caput do seu artigo $2^{\circ}$, que a política urbana tem por escopo "ordenar $o$ pleno desenvolvimento das funções sociais $d a$ cidade e da propriedade urbana", por meio de "diretrizes gerais" que são enunciadas ao longo dos incisos do mencionado dispositivo.

O "Estatuto da Cidade" enfatiza a garantia do direito à propriedade urbana (terra e moradia), ao saneamento ambiental, à infraestrutura urbana, ao transporte e aos serviços públicos, ao trabalho e ao lazer, à participação da população na formulação, na execução e no acompanhamento de planos, programas e projetos de desenvolvimento urbano; à cooperação entre os governos, a iniciativa privada e os demais setores da sociedade no processo de urbanização, em atendimento ao interesse social; ao planejamento do desenvolvimento das cidades, da distribuição espacial da população e das atividades econômicas do Município, objetivando a urbanificação, ${ }^{57}$ a infra-estrutura de equipamentos urbanos e comunitários, transporte e serviços públicos adequados aos interesses e necessidades da população e a ordenação do solo, mediante o controle, uso adequado e compatível dos imóveis urbanos; à preservação do meio ambiente natural e construído, do patrimônio cultural, histórico, artístico, paisagístico, arqueológico e das áreas urbanizadas, à prevenção ao adensamento urbano desprovido de infraestrutura e o incentivo ao desenvolvimento socioeconômico do Município; divisão eqüitativa dos ônus e recuperação dos

${ }^{57}$ Urbanificação como ação correção do processo espontâneo e desordenado da urbanização. investimentos do Poder Público de que tenha resultado a valorização de imóveis urbanos; à segurança da população e a regularização fundiária e, ainda, a igualdade entre os setores público e privado "na promoção de empreendimentos e atividades relativos ao processo de urbanização, atendido o interesse social". ${ }^{58}$

Trata de extenso rol, tanto quantitativo quanto em pretensão e conteúdo, ao procurar cobrir o mais abundante espectro de situações que podem ser encontradas na ambiência urbana, presente e futura.

Traz inovações específicas para o urbanismo e o direito urbanístico, agasalhando institutos já presentes na legislação estrangeira (como o direito de superfície e operação urbana consorciada), e enuncia vários instrumentos ${ }^{59}$ como os planos nacionais, regionais e estaduais de ordenação do território e de desenvolvimento econômico e social; o planejamento das regiões metropolitanas, aglomerações urbanas e microrregiões e o planejamento municipal.

Momentos há em que o legislador deixa o desempenho da atividade urbanística e a ordenação da cidade ao encargo da Administração Pública, já, em outros, alia-a à ação do particular. É o que prevê a operação urbanística consorciada. ${ }^{60}$

\subsection{As operações urbanísticas consorciadas}

Citadas como instrumento de realização da política urbana, as “operações urbanísticas

${ }^{58}$ Tais diretrizes situam-se no artigo $2^{\circ}$, incisos I a XVI, da Lei 10.257/2001.

${ }^{59}$ Artigo $4^{\circ}$, incisos I a VI, letras e parágrafos.

${ }^{60}$ As "operações urbanas consorciadas'estão previstas no artigo $4^{\circ}$ inciso V, letra "p" e artigos 32 a 34 , incisos e parágrafos. 
consorciadas" têm seu conceito dado pelo legislador infraconstitucional como "o conjunto de intervenções e medidas coordenadas pelo Poder Público municipal, com a participação dos proprietários, moradores, usuários permanentes e investidores privados, com o objetivo de alcançar em uma área transformações urbanísticas estruturais, melhorias sociais e a valorização ambiental". ${ }^{61}$

$\mathrm{Se}$, nos primeiros momentos de estruturação e do desenvolvimento do urbanismo e do Direito Urbanístico, a tarefa de ordenar o solo, de planejar a cidade, de executar o planejamento - ainda que com o beneplácito do legislador - era acometida ao Poder Público e tomada como função administrativa, atualmente este mister é compartilhado com os particulares. Portanto, a afirmativa de que as diretrizes do urbanismo, e este como tal, são essencialmente função pública, não está a determinar a exclusão de participações individualizadas.

Adoutrina apregoa e sustenta a importância, o direito de participação dos particulares nas decisões em matéria urbanística, na formação do plano urbanístico e na realização, mediante ações concretas. ${ }^{62}$ A legislação, em especial, evolui nessa direção.

${ }^{61}$ Artigo 32, § $1^{\circ}$, da Lei $10.257 / 2001$.

${ }^{62}$ A respeito a importância a implicações das operações urbanísticas consorciadas, ver BORGES, Alice Gonzalez. Operações Urbanas Consorciadas: os consórcios intermunicipais como instrumentos de realização do estatuto da cidade. In: Direito PúblicoEstudos em homenagem ao Professor Adilson Abreu Dallari, coordenado por Luiz Guilherme da Costa Wagner Junior, Belo Horizonte, Del Rey, p.1 a 12. LOMAR, Paulo José Villela.Operação Urbana Consociada, In: Estatuto da Cidade (Comentários à Lei Federal 10.257/2001), DALLARI, Adilson Abreu e FERRAZ, Sérgio (organizadores), São Paulo, Malheiros, 2002, p. 245 a 275 , dentre outros.
Seguindo essa linha de opinião, Jose Luis Laso Martinez, ${ }^{63}$ com equilíbrio, manifesta-se que “... não se trata de proteger uma esfera individual, mas de colaborar com outros sujeitos, com a própria Administração, em primeiro lugar a estabelecer os benefícios concretos de tipo coletivo que devem derivar de uma atividade administrativa”. Gradualmente, cresce a participação dos particulares em colaboração com a Administração Pública no desempenho de suas funções, numa nítida manifestação de interferência das pessoas privadas no setor público, que Francisco Lliset Borrel ${ }^{64}$ classifica "como justa contrapartida do crescente intervencionismo administrativo".

$\mathrm{Na}$ Espanha essa é uma possibilidade que foi aberta com o advento da Lei do Solo espanhola, de 1975, permitindo aos particulares uma ampla colaboração na execução dos misteres urbanísticos.

Na França, ao lado de outros meios, há "le zone d'aménagement concerté", concebidas como instrumentos essenciais para atender a um duplo objetivo: permite a urbanização de imóveis convenientemente equipados e mal aproveitados e, ainda, permite a realização de operações urbanísticas importantes, diante da atual necessidade de ordenar o desenvolvimento das aglomerações no

${ }^{63}$ MARTINEZ, Jose Luis Laso. Derecho urbanístico. Tomo I, Madrid, Montecorvo, 1981, p. 287. Texto original: “...no se trata de proteger una esfera individual, sino de colaborar con otros sujetos, con Ia propia Administración, en primer lugar, a estabelecer Ias ventajas concretas de tipo colectivo que han de derivar de una actividad administrativa”.

${ }^{64}$ BORREL, Francisco Lliset. La actividad urbanística de los particulares. Madrid, Montecorvo, 1975, p. 91. Texto original: “como justa contrapartida deI creciente intervencionismo administrativo”. 
espaço e no tempo. ${ }^{65}$ É uma parceria das administrações locais e agentes públicos e privados, cuja ação é submetida a normas de direito urbanístico.

As hipóteses e possibilidades de participação dos particulares são variadas e dependem de cada sistema, sempre obedecendo a critérios predeterminados pelo ordenamento jurídico. Isto, todavia, não descaracteriza o urbanismo como uma função pública.

Vários países adotam e, há algum tempo, essa divisão de ônus - e também de bônus no que tange ao urbanismo e à ordenação do solo.

No Direito pátrio, por meio das “operações urbanísticas consorciadas" participação dos privados é institucionalizada e, naturalmente, submetida a determinadas condições.

Em primeiro lugar, o uso das operações urbanísticas consorciadas tem objetivos claros: "transformação urbanística estrutural, melhorias sociais e a valorização ambiental", em uma dada área prevista em lei específica e com base no plano diretor. Em outras palavras, há a exigência do plano diretor, que genericamente disciplina a ordenação do solo, mediante a posterior edição de lei específica que poderá - facultativa, logo, não obrigatoriamente - prever área na qual incidirão as intervenções e medidas, pela atuação coordenada do Poder Público e dos particulares.

No tratamento legislativo dado ao assunto, mesmo com a inserção definitiva

${ }^{65}$ Circulaire $\mathrm{n}^{\text {o }}$ 69-67, de 4 juin 1969. DEMEURE, Sylvain, MARTIN, Jean Yves e RICHARD, Michel-La ZAC - Zone d'aménagement concerte. Editions du Moniteur, Paris, 2004, p.I. dos particulares e do investimento privado, o interesse público se sobrepõe ao particular, não só pelos objetivos - transformações urbanísticas estruturais, melhorias sociais e a valorização ambiental -, requisitos - lei municipal especifica, em área prevista no plano diretor, atendimento econômico e social da população diretamente afetada, Estudo Prévio de Impacto Ambiental e o detalhamento das ações - e controle compartilhado pela sociedade, mas, sobretudo, pela interceptação sistemática que deflui das diretrizes gerais constantes do art. $2^{\circ}$, do "Estatuto da Cidade". Portanto, é atuação que deve ser regida por critérios de interesse público, inclusive no que concerne à "emissão de certificados de potencial adicional de construção”, sob pena de ilegalidade e inconstitucionalidade.

Essas ações, que congregam o atuar do Poder Público e dos particulares qualificados de diversas formas, ou seja, como "proprietários, moradores, usuários permanentes e investidores privados" -, em prol da urbanização, e que estão rigorosamente atrelados ao interesse coletivo, executando o planejamento urbanístico, atendendo ao bem-estar da coletividade, a preservação do meio ambiente e da vida digna dos indivíduos, as operações urbanas consorciadas (compreendendo desde objetivos mais básicos, como infra-estrutura viária e sanitária, ao mais complexo, como a alteração da conformação e da ocupação do solo) podem receber a devida adequação, complementarem-se e dar executoriedade à determinação que consta da Constituição da República de 1988 e das diretrizes do Estatuto da Cidade. 


\section{CONSIDERAÇÕES FINAIS}

Vê-se, embora ainda não definido, porque mutável sem descanso, o retrato evolutivo no qual a propriedade privada, recebeu, passo a passo, em seu invólucro e em sua essência, cinzeladas e que tiveram o condão de esculpi-la com a feição menos individualista e mais solidária. Norteada pela harmonia entre o interesse privado e o público - cujo processo não é sem conflitos -, unidos para um fim único, que é dignidade do ser, todo o instrumental jurídico está à disposição do Poder Público para atender a uma realidade peculiaríssima: a da cidade e tudo o que consigo traz. Ansiedades, conflitos e anseio de paz e bem-estar.

Avanços científicos e legislativos aconteceram, no Estado e na sua estrutura opera-se significativa mudança, em especial no que concerne a missões que lhes são próprias e, por intermédio de vários mecanismos - uns bons, outros, maus; uns efetivos, outros que se mostram inúteis; alguns legítimos, outros espúrios - persegue-se o atendimento ao indivíduo, à sua dignidade, ao interesse da coletividade, ao interesse público. E no cerne desse emaranhado houve e sempre haverá, surgindo e ressurgindo, de forma lenta ou repentina, a propriedade. Ou seja, nas palavras de Stefano Rodotà, ${ }^{66}$ de tempos em tempos há um "renascimento da questão proprietária” e que "não é um artigo de lei, mas um evento social" que pode desmontar

${ }^{66}$ RODOTÀ, Stefano. Il terribile diritto - Studi sulla proprietà privata, Bologna, Il Mulino, 1990, p. 15.Texto original: “...la rinascita da questão proprietária”....” non è um articolo di legge, ma uma vicenda sociale...”... 'l'enigma della proprietà' rimane intatto davantti a noi... e ripropone l'antica grandezza della questione”. toda uma construção a respeito do tema. Ecomplementa que "o 'enigma da propriedade' permanece intacto diante de nós... e re-propõe a antiga grandeza dessa questão”.

Seja no cenário urbanístico ou da atuação dos privados onde há o "capital”, nas esferas pública ou privada, em ambas, sempre a propriedade estará presente, na condição de produtora de riqueza ou do interesse coletivo quaisquer manifestações, e permanentemente cambiante, submetida às formas que lhe venham dar o ordenamento jurídico. 